This is the accepted manuscript version of an article published as: Fraser, Suzanne and Treloar, Carla and Bryant, Joanne and Rhodes, Tim. 2014. Hepatitis C prevention education needs to be grounded in social relationships. Drugs: Education, Prevention and Policy. 21 (1): pp. 88-92. DOI: 10.3109/09687637.2013.776517

\title{
Hepatitis C prevention education needs to be grounded in social relationships
}

Fraser, S., Treloar, C., Bryant, J.and Rhodes, T.

Contemporary Drug Problems, 2013

\section{Abstract}

Most hepatitis $\mathrm{C}$ transmission occurs through the sharing of equipment used for injecting drugs, and in many settings, the majority of equipment sharing occurs between sexual partners. Despite this, few health promotion materials directly address sexual partnerships, couples or social relationships in general. This blindspot is one example of the ways in which prevention education in the area of drug use would benefit from careful rethinking. Focusing on the case of Australia, we argue that hepatitis C prevention education insufficiently acknowledges or mobilise social relationships, social dynamics and social contexts in its efforts to prevent hepatitis $C$ transmission. This can lead it to reproduce the conditions for the very problems it seeks to solve. We further argue that hepatitis $C$ prevention education is insufficiently attentive to its own social location, drawing too little on stakeholder expertise. Its effectiveness relies upon its social context, including the collaborative input and engagement of affected communities and other stakeholders. Better recognising this would produce a stronger foundation for developing prevention strategies. As we conclude, this social foundation for hepatitis C prevention could be articulated into national, collaboratively developed guidelines on effective communication in hepatitis $C$ and injecting drug use risk.

Keywords: hepatitis $\mathrm{C}$, health promotion, social relationships, sexual partnerships 


\section{Hepatitis C health promotion needs to be grounded in social relationships}

Hepatitis C is a blood-borne virus which, in developed countries, is transmitted primarily through injecting drug use. An estimated 170 million people live with the disease worldwide. In Australia, approximately 200,000 people are thought to be chronically infected, and an estimated 9,700 new infections occur each year (Razali et al., 2007). As in other developed countries, most chronic infections (88.6\%) are found among people who inject drugs (PWID) (Razali et al., 2007), most transmission occurs through the sharing of equipment used for injecting drugs, and much equipment sharing occurs between sexual partners (Iversen \& Maher, 2012). Despite this, prevention education targeting PWID rarely addresses sexual partnerships or couples directly (Dwyer et al., 2011). Instead, the primary focus is on individuals, addressed in isolation, as if free of social relationships and social contexts. Where social and sexual relationships feature, they are envisaged largely as a source of risk or infection (Dwyer et al., 2011; Fraser, 2004). Why is prevention education apparently blind to the importance of people's social relationships in mediating hepatitis $\mathrm{C}$ ? This blindspot indicates the need to rethink hepatitis C prevention education among PWID. In this commentary we draw on the example of Australia to explore this issue, but our case also has resonances for other settings similarly characterised by predominantly individualising hepatitis C prevention education. We argue that hepatitis C prevention education needs to recognise better the social nature of injecting drug use, but more than this, that prevention education is itself a social process. First, using the example of gender and intimate sexual relationships we show how injecting risk can be socially produced, and point out that this continues to be ignored by prevention education. Second, we explore how the limitations and innovations of prevention education, the assumptions it makes and the new insights it offers, its effectiveness or otherwise, are the product of its social location and of social resources such as the ideas and support its draws on. As we will conclude, this social foundation for hepatitis $\mathrm{C}$ prevention could be articulated in national, collaboratively developed guidelines on effective communication in hepatitis $\mathrm{C}$ and injecting drug use risk. 
A recent review of Australian hepatitis $C$ prevention education literature highlights the concerns we focus on here, identifying a pressing need to rethink current assumptions of all kinds behind the design and content of resources (Winter et al., 2011). The review found that Australian hepatitis $\mathrm{C}$ prevention education literature is rarely sufficiently attentive to the socially produced nature of risk practices, identities and social relationships, and consequently does not speak well to the diversity of lived experiences among different networks of PWID. The review also notes that widespread practices of injecting in groups (where social conventions or setting shape practices and hence risk) tend to be ignored or simply discouraged, so that little attention is paid to enhancing safety in such settings. The authors point out that individuals often take specific roles in injecting, and that these are shaped by their relationships with others, especially as this relates to gender and intimate heterosexual relationships.

\section{Heterosexual partnerships and gender}

Research suggests that gender and intimate sexual relationships play an important role in shaping injecting drug use. In 2011, Australian surveillance data indicated that the largest proportion of needle sharing incidents (approximately 50\%) occurred between sexual partners (Iversen \& Maher, 2012), and similar patterns have been noted elsewhere (Cao \& Treloar, 2006; Bryant et al., 2010). Beyond the sharing of needle and syringes, a significant proportion of hepatitis $\mathrm{C}$ transmissions between sexual partners is also thought to occur through the sharing of ancillary equipment such as filters, swabs, spoons and tourniquets (Bryant et al., 2010). These studies suggest that the sexual partnership requires close attention in hepatitis $C$ research and, in turn, in prevention education efforts. Epidemiological research also indicates that patterns of hepatitis $\mathrm{C}$ risk are distributed differently for women and men. Women have been found to:

- be less likely to inject alone (Sherman, Latkin, \& Gielen, 2001); 
- be more likely to have a sexual partner who also injects drugs (Choi, Wah Cheung, \& Chen, 2006; Davies, Dominy, Peters, \& Richardson, 1996; Evans, Hahn, PageShafer, Lum, Stein, Davidson et al., 2003; Freeman, Rodriguez, \& French, 1994);

- go 'second on the needle' when sharing with a male sexual partner (Grund, Friedman, Stern, Jose, Neaigus, Curtis et al., 1996);

- be injected by a male sexual partner (Choi, Wah Cheung, \& Chen, 2006; Evans, Hahn, Page-Shafer, Lum, Stein, Davidson, et al., 2003; Thiede, Hagan, Campbell, Strathdee, Bailey, Hudson et al., 2007; Freeman, Rodriguez, \& French, 1994; Bennett, Velleman, Barter, \& Bradbury, 2000; Rhodes, Davis, \& Judd, 2004; Strathdee, Patrick, Archibald, \& Ofner, 1997; Wechsberg, Dennis, \& Stevens, 1998; Maher \& Hudson, 2007), and;

- have been introduced to injecting by a male sexual partner (Evans, Hahn, PageShafer, Lum, Stein, Davidson, et al., 2003; Bryant \& Treloar, 2007; Crofts, Louie, Rosenthal \& Jolley, 1996; Diaz, Vlahov, Edwards, Conover \& Monterroso, 2002). While these studies are valuable in describing broad patterns of risk practice among men and women in sexual relationships, they are unable to tell us much about precisely why and how sexual partners engage in such practice. Further, in comparing women and men, epidemiological studies have at times reproduced gender stereotypes, reading agency and decision-making through unexamined gender norms. They have rarely, if ever, conceptualised the sexual relationship as a unit of analysis in its own right and a space in which risk practices such as needle sharing do not simply occur but are produced (Rhodes, \& Quirk, 1998). Likewise, this research is limited by its tendency to treat gender, injecting practice and heterosexual relationships as independent phenomena instead of recognising that each helps to produce the other.

\section{The social relations of hepatitis $\mathrm{C}$}


Qualitative sociological research goes some way towards illuminating the ways gender, injecting practice and heterosexual relationships interact. Several studies have suggested that sexual relationships shape the ways PWID think about, discuss and act on blood-borne virus prevention. Needle sharing between sexual partners can result in or act as a sign of emotional bonding, commitment, fidelity, mutual trust and shared intimacy (Davies, Dominy, Peters, \& Richardson, 1996; Rhodes, \& Quirk, 1998; Habib, 2003; Lakon, Ennett, \& Norton, 2006; MacRae, 2000; Simmons, \& Singer, 2006). Refusal to share can introduce the suggestion of distrust and a denial of intimacy (Barnard, 1993; Unger, Kipke, De Rosa, Hyde, Ritt-Olson, \& Montgomery, 2006; Dear, 1995). In these ways, sexual relationships can 'give rise to, and influence, risk behaviour' (p.158) (Rhodes, \& Quirk, 1998). Dynamics such as these can make discussion of hepatitis C prevention difficult. Indeed, there is some evidence that PWID engage in little or no discussion of hepatitis $C$ serostatus within sexual partnerships (Seear, Gray, Fraser et al., 2012; Ennett, \& Norton, 2006; Rhodes, \& Quirk, 1998; Lakon, Dear, 1995).

Qualitative research also elucidates the ways sexual relationships and drug use shape each other in indirect ways relevant to hepatitis $\mathrm{C}$ prevention. For example, regular drug use is a central feature of some sexual relationships (Rhodes, \& Quirk, 1998). In this context reducing or ceasing injecting drug use (and thus potentially reducing the risk of transmission) can prove difficult to negotiate for one partner alone (Rhodes, \& Quirk, 1998). Some research suggests that this conflict is felt more profoundly by women. Challenging relationship expectations can lead to violence, jeopardise sources of income, drugs and other resources, and threaten women's subsistence more broadly (Freeman, Rodriguez, \& French, 1994; Bourgois, Prince, \& Moss, 2004; Rhodes, Singer, Bourgois, Friedman, \& Strathdee, 2005). The potential losses associated with disrupting existing relationship dynamics and altering injecting practice can be especially stark for women who live on the street in that their male partners sometimes provide physical protection from attack by other men (MacRae, 2000; Bourgois, Prince, \& Moss, 2004). As in other heterosexual 
relationships, gender norms and expectations relating to, for example, control over economic resources or to physical aggression, can shape relationships between PWID, and the choices each party to a relationship makes.

While this literature does not describe exhaustively the various issues at play in the gendered social dynamics of injecting drug use in sexual partnerships, it makes clear that gender, social relationships and sexual intimacy all shape injecting practices and decisions. Further, in indicating the role of norms and expectations, socially informed patterns of conduct, and the socially produced meaning of intimacy and fidelity, it makes clear that the dynamics of safe injecting are not only determined by individual choices but by a complex array of social conventions, expectations and values. In this respect it makes little sense to conceive prevention at the level of the individual alone, or to ignore the complexities of social and sexual relationships in injecting drug use, as appears to be the case in existing prevention educatioin materials (Dwyer et al., 2011)

\section{Rethinking hepatitis C prevention education}

The research explored here suggests two limitations in current approaches to hepatitis $\mathrm{C}$ prevention among PWID. The first, as demonstrated by the example of gender and intimate relationships, is insufficient acknowledgement or mobilisation of social relationships, social dynamics and social contexts in messages and resources aimed at preventing hepatitis C. Drug harms are now much more commonly understood to be shaped by social and structural conditions, of which social relationships and practices are an integral part (Rhodes, 2009). Calls for social intervention and community action in HIV prevention are now well established (Blakenship et al., 2002; Gupta et al., 2008), even if arguably weaker or more recent among PWID. The adverse consequences of failing to acknowledge drug harms as socially contingent are more widely acknowledged. Now also better recognised is the blame fostered by interventions that treat responsibility as a matter for individuals rather than as shared across actors and social relations (Fraser, 2004). This tendency is also thought to 
contribute to the message fatigue identified among some groups targeted for change (Treloar, valentine and Fraser, 2011). These are not new ideas, yet hepatitis C prevention education continues to neglect the 'social'.

The second, related, limitation concerns the extent to which the hepatitis C prevention education development processes draw on stakeholder expertise and experience. Yes, injecting drug use is a social practice, but so too is the prevention education that seeks to address it. By this we mean two slightly different things. First, prevention education is conceived in a social context: it is shaped by, and often includes, unexamined social norms and expectations. This is especially relevant to issues of gender and sexuality, which find expression in a range of concerning ways in hepatitis $C$ prevention education materials (such as in images of the female body as a 'biohazard' [Fraser and Seear, 2011]). Second, prevention education can be improved by the contribution of insights from those in society most affected by, and informed on, the issues it addresses (this would itself constitute a social process). Producing new prevention education materials, or updating existing ones requires regular, systematic review by a diverse group of stakeholders (members of affected communities, service providers, academics, policy makers), and well-articulated expectations and standards for the design and content. Failing to proceed in this way can instate as many problems as they solve, at times reproducing unhelpful assumptions.

In our view, there is a pressing need for innovations that more explicitly recognise the social nature of prevention education. The formalisation of stakeholder integration into the development of resources is one such innovation. A formal process would draw in a wider range of insights, and improve design and delivery. We consider Winter et al.'s (2011) report a useful starting point for thinking through this innovation. The report recommends the development of collaboratively produced national guidelines on effective communication in hepatitis $C$ and injecting drug use risk. These guidelines would be established and revised through a regular consultation process, allowing scrutiny and debate about the language, 
assumptions and imagery used in health promotion materials. In this way, the process would mobilise shared expertise to help circumvent the misuse of unexamined concepts such as those to do with gender, individuality, risk, responsibility and other key issues. The process would also highlight the need for continuous consultation and communication between stakeholders.

In conclusion, recognising the limitations of existing prevention education literature offers us two main opportunities. The first opportunity is to address the persistent shortcomings identified by the research; for example, to spell out the fact that individuals, groups and society as a whole all have responsibilities in preventing the transmission of hepatitis $\mathrm{C}$, to include more images of couples and groups, and more advice on navigating injecting in partnerships and social settings. The second, broader, opportunity is to recognise that habits of this kind - relying on assumptions, tending to homogenise readers and so on - are a recurring dynamic, an occupational hazard as it were. They need regular attention and reflection via a mechanism such as the production and review of national guidelines. It is in both these respects - in recognising and accommodating the social nature of injecting drug use, and in recognising that prevention education is itself also social - that hepatitis $\mathrm{C}$ prevention education needs better grounding in social relationships.

References

Barnard, M. (1993). Needle sharing in context: Patterns of sharing among men and women injectors and HIV risks. Addiction, 88, 805-2.

Bennett, G., Velleman, R., Barter, G. \& Bradbury, C. (2000). Gender differences in sharing injecting equipment by drug users in England. AIDS Care, 12(1), 77-87. 
Bourgois, P., Prince, B. \& Moss, A. (2004). The everyday violence of hepatitis C among young women who inject drugs in San Francisco. Human Organization, 63(3), 253-64.

Bryant, J., Brener, L., Hull, P. \& Treloar, C. (2010). Needle sharing in sexual relationships: Serodiscordance and the gendered character of injecting. Drug \& Alcohol Dependence, 107, 182-7.

Bryant, J. \& Treloar, C. (2007). The gendered context on initiation to injecting drug use: evidence for women as active initiates. Drug \& Alcohol Review, 26, 287-93.

Cao, W. \& Treloar C. (2006). Comparison of needle and syringe programme attendees and non-attendees from a high drug using area in Sydney, New South Wales. Drug \& Alcohol Review, 25, 439-44.

Choi, S., Wah Cheung, Y. \& Chen, K. (2006). Gender and HIV risk behavior among intravenous drug users in Sichuan Province, China. Social Science \& Medicine, 62, 1672-84.

Crofts, N., Louie, R., Rosenthal, D. \& Jolley, D. (1996). The first hit: Circumstances surrounding initiation into injecting. Addiction, 91(8),1187-96.

Davies, A., Dominy, N., Peters, A. \& Richardson, A. (1996).Gender difference in HIV risk behaviour of injecting drug users in Edinburgh. AIDS Care, 5, 517-27.

Dear L. (1995). Negotiated safety: What you don't know won't hurt you, or will it? Drug \& Alcohol Review, 14, 323-9. 
Diaz, T., Vlahov, D., Edwards, V., Conover, S. \& Monterroso, E. (2002). Sex-specific differences in circumstances of initiation into injecting-drug use among young adult Latinos in Harlem, New York City. AIDS Behaviour, 6, 117-22.

Dwyer, R., Fraser, S. \& Treloar C. (2011). Doing things together?: Analysis of health promotion materials to inform hepatitis C prevention among couples. Addiction Research \& Theory, 9(14), 352-361.

Evans, J., Hahn, J., Page-Shafer, K., Lum, P., Stein, E., Davidson, P., et al. (2003). Gender differences in sexual and injection risk behaviour among active young injection drug users in San Francisco (the UFO Study). Journal of Urban Health, 80, 137-46.

Fraser, S. (2004). 'It's your life!': Injecting drug users, individual responsibility and hepatitis C prevention. Health, 8(2), 199-221.

Fraser, S.\& Seear, K. (2011). Making disease, making citizens: The politics of hepatitis C. Aldershot, Ashgate.

Freeman, R., Rodriguez, G. \& French, J. (1994). A comparison of male and female intravenous drug users' risk behaviors for HIV infection. American Journal of Drug \& Alcohol Abuse, 20(2), 129-57.

Griesbach, D., \& Taylor, A. (2009). Educational interventions to prevent hepatitis C: A review of the literature and expert opinion. Edinburgh: NHS Health Scotland.

Grund, J-P., Friedman, S., Stern, L., Jose, B., Neaigus, A., Curtis, R., et al. (1996). Syringemediated sharing among injecting drug users: patterns, social context and implications for transmission of blood-borne pathogens. Social Science \& Medicine, 42(5), 691-703. 
Habib, S. (2003). Understanding the context of risk practices among injecting drug users: implications for hepatitis C prevention. Australian Journal of Social Issues, 38(1), 1-17.

Iversen, J. and Maher, L. (2012). Australian Needle and Syringe Program National Data Report 2007-2011. The Kirby Institute, University of New South Wales, 2012.

Lakon, C., Ennett, S. \& Norton, E. (2006). Mechanisms through which drug, sex partner, and friendship network characteristics relate to risky needle use among high risk youth and young adults. Social Science \& Medicine, 63, 2489-99.

MacRae, R. (2000). Gendered power dynamics and HIV risk in drug-using sexual relationships. AIDS Care. 12(4), 505-15.

Maher, L. \& Hudson, S. (2007). Women in the drug economy: A metasynthesis of the qualitative literature. Journal of Drug Issues. 37, 805-26.

Razali, K., Thein, H., Bell, J., Cooper-Stanbury, M., Dolan, K., Dore, G., et al. (2007). Modelling the hepatitis C virus epidemic in Australia. Drug \& Alcohol Dependence, 91(2-3), 228-35.

Rhodes, T., Davis, M. \& Judd, A. (2004). Hepatitis C and its risk management among drug injectors in London: renewing harm reduction in the context of uncertainty. Addiction, 99, 621-33.

Rhodes, T. \& Quirk, A. (1998). Drug users' sexual relationships and the social organisation of risk: The sexual relationship as a site of risk management. Social Science \& Medicine, 2(46), 157-69. 
Rhodes, T., Singer, M., Bourgois, P., Friedman, S. \& Strathdee, S. (2005). The social structural production of HIV risk among injecting drug users. Social Science \& Medicine, 61, 1026-44.

Seear, K., Gray, R., Fraser, S., Treloar, C., Bryant, J., Brener, L. (2012). Rethinking safety and fidelity: The role of love and intimacy in hepatitis C transmission and prevention. Health Sociology Review, 21(3): 272-286.

Sherman, S., Latkin, C. \& Gielen, A. (2001). Social factors related to syringe sharing among injecting partners: a focus on gender. Substance Use \& Misuse, 36(14), 2113-36.

Simmons, J. \& Singer, M. (2006). I love you . . . and heroin: care and collusion among drugusing couples. Substance Abuse Treatment Pr., 1, 7-19.

Strathdee, S., Patrick, D., Archibald, C. \& Ofner, M. (1997). Social determinants predict needle-sharing behaviour among injection drug users in Vancouver, Canada. Addiction, 92, $1339-47$.

Thiede, H., Hagan, H., Campbell, J., Strathdee, S., Bailey, S., Hudson, S., et al. Prevalence and correlates of indirect sharing practices among young adult injection drug users in five U.S. cities. Drug \& Alcohol Dependence, 91(S1), S39-S47.

Treloar, C., Valentine, K., Fraser, S., 2011, Social inclusion and hepatitis C: Exploring new possibilities for prevention, Expert Review of Anti-Infective Therapy, 9(4), 397-404. 
Unger, J., Kipke, M., De Rosa, C., Hyde, J., Ritt-Olson, A. \& Montgomery, S. (2006). Needlesharing among young IV drug users and their social network members. The influence of the injection partner's characteristics on HIV risk behavior. Addictive Behaviors, 31, 1607-18.

Wechsberg, W., Dennis, M. \& Stevens, S. (1998). Cluster analysis of HIV intervention outcomes among substance abusing women. American Journal of Drug and Alcohol Abuse. 24(2), 239-57.

Winter, R., Fraser, S., Booker, N. \& Treloar, C. (2011). Technical review of hepatitis C health promotion resources. Monograph 5/11. Sydney: National Centre in HIV Social Research. 